\title{
Further studies on the fairy shrimp genus Branchinella (Crustacea, Anostraca, Thamnocephalidae) in Western Australia, with descriptions of new species
}

\author{
Brian V. Timms \\ Honorary Research Associate, Australian Museum, 6-9 College Street, \\ Sydney, New South Wales 2000, Australia.
}

\begin{abstract}
Four new species of Branchinella are described from Western Australia: B. multidigitata sp. nov., B. papillata sp. nov., B. pinderi sp. nov. and $B$. vosperi sp. nov. The name $B$. moraei is corrected to $B$. moraeac. New records of $B$. compacta and $B$. pinnata, previously known from eastern Australia, are also presented, bringing the number of Western Australian Branchinella species to 25. Fourteen of these are endemic, by far the greatest for any Australian state. This biodiversity hotspot for this genus and family is facilitated by localised distributions latitudinally and not by niche diversification; there are few sympatric occurrences. Extremely turbid waters are common habitats. Some species distributed across the continent exhibit morphological differences in Western Australia.
\end{abstract}

\section{INTRODUCTION}

The genus Branchinella was established by Sayce (1903) to accommodate Branchipus australiensis Richters, 1876, at the time known only from inland Queensland. This species, now known to be widespread (Timms, 2004), was first recognised in Western Australia by Wolf (1911) (as B. eyrensis). Wolf described the endemic B. longirostris in 1911, Dakin reported $B$. occidentalis (as B. australiensis var. occidentalis) in 1914, and Schwartz extended the list with B. dubia (as Podochirus dubia) in 1917. Milner bought this total to six in 1929 with the description of $B$. wellardi and $B$. mirabilis, the latter synonymised with $B$. frondosa Henry, 1924 . The last of these early taxonomists was Linder (1941) who described $B$. apophysata, $B$. denticulata, $B$. nichollsi and $B$. simplex, all endemics to Western Australia, and recognised the presence of widespread $B$. affinis (as $B$. affinis var. wonganensis). Of the eleven species then known in Western Australia, five were endemic to the area.

More recently, Geddes (1981) described B. basispina from Western Australia and reported the widespread $B$. Iyrifera to the state's fauna. Timms (2002) bought the state's total to 18 , with the description of $B$. complexidigitata, $B$. halsei, $B$. kadjikadji, $B$. nana, and recognition of the presence of B. proboscida Henry, 1924. Since then, Timms (2005) described B. mcraei from the Pilbara. Of these 19 species, 10 are endemic to Western Australia, by far the greatest number of any Australian state or territory /Queensland, South Australia and the Northern Territory have one each, the other states none, though some species are localised around state borders (Timms, 2004, 2005)]. Together with six more species of Branchinella added in this paper, about 15 species of Parartemia (six described and nine known undescribed species (Timms, 2004)) and at least one species of Streptocephalus (Timms, 2004, and unpublished data), this makes Western Australia one of the hot spots of Anostracan diversity in the world (Belk, 1998; Timms, 2002).

Branchinella is by far the most common and speciose genus of freshwater anostracan in Australia. It is defined by characteristics of its gonopods and brood pouch (Geddes, 1981; Rogers, 2006). Species are separated using characters mainly of the male second antennae and frontal appendage, and to a lesser extent of the gonopod bases and female second antennae (Timms, 2004).

Since a review of Western Australian Branchinella (Timms, 2002), staff from the Western Australian Department of Environment and Conservation have made extensive collections, mainly in the northwest of the state. Additional collections have also been made by the author in the Esperance area. It is the aim of this paper to document the new species and records, with a particular emphasis on the uniqueness of the Western Australian anostracan fauna and of its differences to that in eastern Australia.

\section{METHODS}

Extensive collections were made in the southeastern quarter of Western Australia (Figure 1) in the winter-spring of 2004 and 2005, finding 


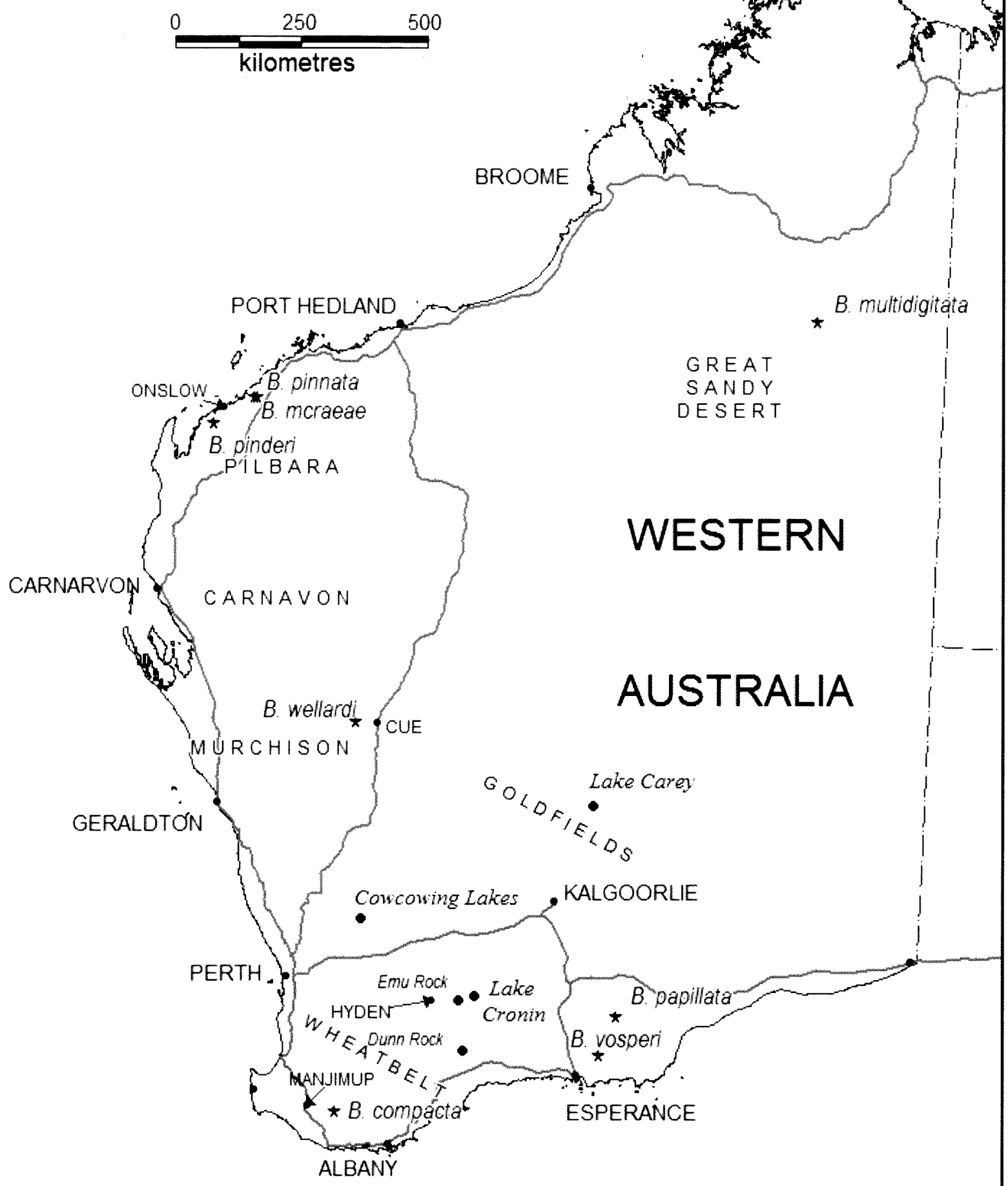

Figure 1 Map of Western Australia showing most localities mentioned in the text. Places shown as dots, species sites as asterisks. 
Branchinella at 72 sites. Also data for 2003-04 from a study of Lake Carey wetlands by Timms et al. (2007) and unpublished 2006 data are included. Only the most significant of these sites are noted here. Additionally, in 2005 Roger Hearn of the Department of Environment and Conservation, Manjimup, provided specimens from near Unicup Lake; Adrian Pinder and Jane McRae, of Department of Environment and Conservation, Woodvale, added material from the Pilbara, and I found a mislabelled new species in the Western Australian Museum.

A camera lucida attached to a stereoscopic microscope was used to draw whole or part specimens and a digital camera to obtain correct proportions of the thoracopods under a high powered compound microscope.

Abbreviations used: $\mathrm{AM}=$ Australian Museum; DEC, Western Australia's Department of Environment and Conservation; WA $=$ Western Australia; and WAM = Western Australian Museum.

\section{SYSTEMATICS}

\section{Class Crustacea Brünnich, 1772}

\section{Order Anostraca, Sars, 1967}

\section{Family Thamnocephalidae Packard, 1883}

\section{Branchinella Sayce, 1903}

Branchinella Sayce, 1903: 233.

\section{Type species}

Branchipus australiensis Richters, 1876, by subsequent designation.

\section{Branchinella compacta Linder Figure 2}

Branchinella compacta Linder, 1941: 245-247, figure 31; Geddes, 1981: 261-262, figure 4; Timms, 2004: 44, 66, figures 57, 87 .

\section{Material examined}

Australia: Western Australia: $5 \delta, 5 q$, small lake south of Unicup Lake in Unicup Nature Reserve, about $55 \mathrm{~km}$ east of Manjimup, 34.21'41"S, $116^{\circ} 43^{\prime} 22^{\prime \prime} \mathrm{E}, 19$ August 2005, R. Hearn (WAM C38276); New South Wales: 5 d, 5 \&, Avon Lake, Monaro, $36^{\circ} 43^{\prime} \mathrm{S}, 149^{\circ} 03^{\prime} \mathrm{E}, 19$ December, 1989, B.V. Timms (AM P74345).

\section{Remarks}

Previously, B. compacta was known only from south-eastern Australia, from lakes in the Corangamite district in western Victoria, from Lake Omeo in eastern Victoria, and also from the Monaro in New South Wales (Geddes, 1981; Timms, 2004). Most of these records are from hyposaline sites (1.5-16 g/L). The site from the Unicup Nature Reserve, near Manjimup (Figure 1) in southwestern Western Australia is a shallow lake (15 ha, $<1 \mathrm{~m}$ deep), alkaline ( $\mathrm{pH} 7.5$ to 9) and significantly, an elevated salinity of 4 to $4.5 \mathrm{mS} / \mathrm{cm}(\approx 2.7 \mathrm{~g} / \mathrm{L})$ when Branchinella was present (R. Hearn, pers. comm.).

The mature Unicup specimens are slightly larger than those described by Linder (1941), the five males averaging $28.9 \mathrm{~mm}$ (range $26-31.5 \mathrm{~mm}$ ), and five females averaging $31.8 \mathrm{~mm}$ (range $30-34 \mathrm{~mm}$ ). Though Linder's data was equivocal, this suggests the females are a little larger than the males, as is typical of the closest relatives of $B$. compacta (Geddes, 1981).

Morphology of the Unicup specimens is almost identical with that of the Victorian specimens. Male head and second antenna (Figure 2A) are robust with relatively large distal antennomeres, well armed with transverse ridges on the medial surface. As Linder (1941) remarked there are dorsomedial and ventromedial swellings on the free parts of the proximal antennomere and there is no trace of any frontal appendage.' The gonopods (Figure 2B) are long (equivalent to a little more than three abdominal segments) and have a row of triangular spines laterally and a narrow field of sharper spines medially. As Geddes (1981) noted the gonopods are composed of two, not three parts (Linder, 1941); a short basal part with a triangular spine dorsomedially, and a long distal part with the lateral and medial spines. Neither Linder (1941) nor Geddes (1981) mention the oval-shaped hollow lateral to each gonopod base. Such hollows are of unknown function and are uncommon in Branchinella, being found only in B. hattahensis Geddes, 1981, B. buchananensis Geddes, 1981 (Timms, 2005) and in two new species described below.

The Unicup females (Figure 2C,D) accord with the descriptions given by Linder (1941) and Geddes (1981), though in the Unicup specimens the second antenna apex narrows unevenly to have a shoulder and a sharper apex, whereas in eastern populations, the apex narrows evenly. Significantly, all populations have outgrowths and dorsal spines on the first genital segment, all of which probably play a role in amplexus (Rogers, 2002). This is the only Branchinella species with such body ornamentation, though a new species described below has even greater surface complexities on the last thoracic and first genital segments. The Unicup specimens also have small lateral outgrowths on the $11^{\text {th }}$ thoracic segment to compliment those on the first genital segment.

The specimens (Figures 2E, F) from Monaro in southeastern New South Wales, differ slightly (Figures 1E, F). Males from all three known $B$. 

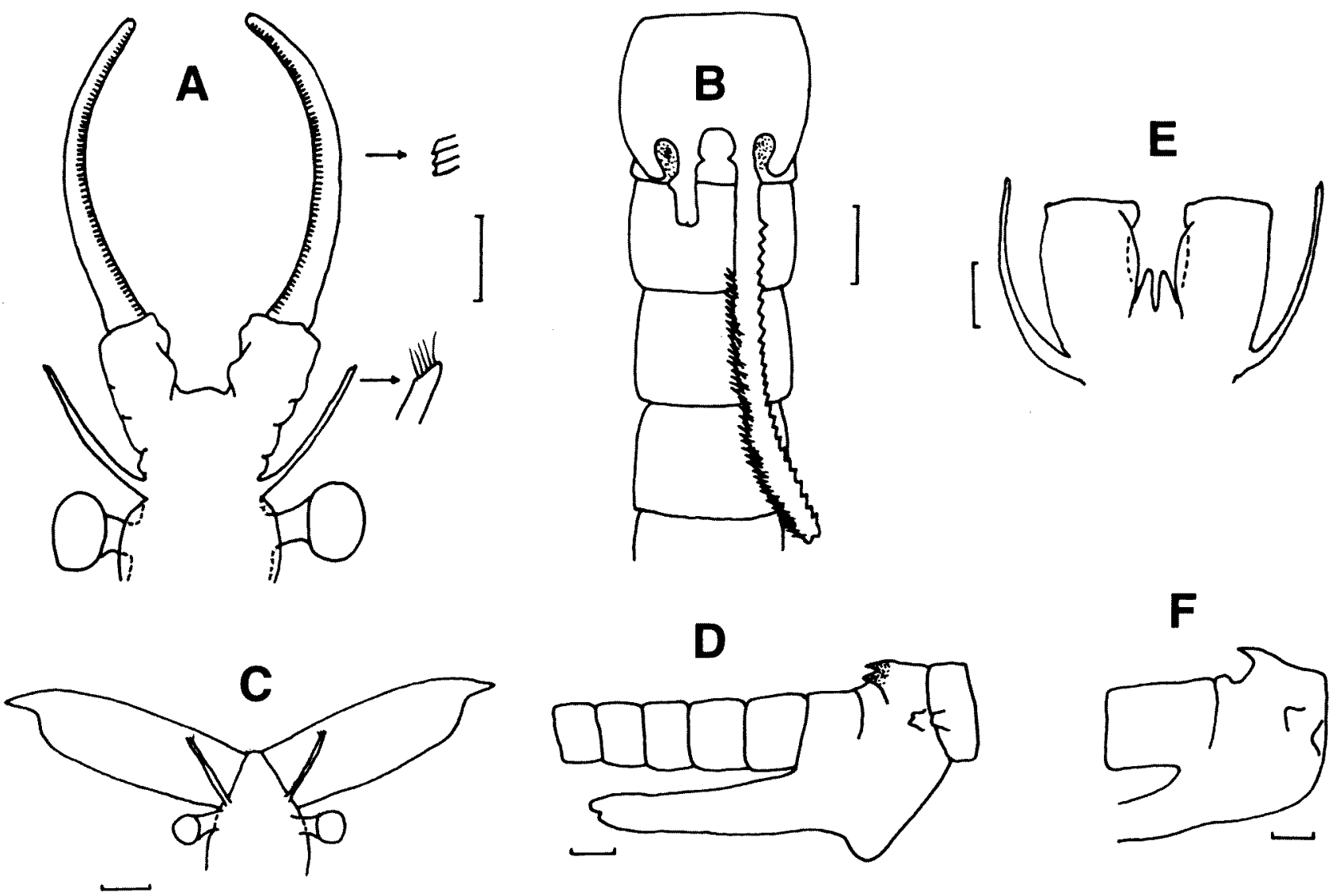

Figure 2 Branchinella compacta Linder: A, dorsal view of male head; B, ventral view of male genital segments and adjacent abdominal segments with one gonopod verted; C, dorsal view of female head; D, lateral view of female genital segments with brood pouch, and of adjacent thoracic segment and abdominal segments; $E$, male from Monaro, New South Wales showing first and basal segment of second antenna and the small frontal appendage; F, female from Monaro, New South Wales. Lateral view of genital segments. Scale bars 1 $\mathrm{mm}$.

compacta sites (Avon Lake, Buckleys Lake, Muddah Lake), all have a very short frontal appendages. Otherwise they have the features described by Linder based on Victorian specimens. Females also have the typical features of $B$. compacta, except lateral bulges on the first genital segment are slightly different, but this could be due to preservative distortion. There are no lateral outgrowths on thoracic segments. They are also relatively large, with the females much bigger than the males (mean length of males $29.2 \mathrm{~mm}$ (range $27-33 \mathrm{~mm}$ ); mean length of females $36.4 \mathrm{~mm}$ (range $25.5-40.5 \mathrm{~mm}$ ).

The Unicup site is unique; its hydrology is different from other regional wetlands and no other ansotracans were found in a study of them ( $R$. Hearn, pers. comm.). It is likely therefore this population is isolated and perhaps unique. Though the site is protected in a Nature Reserve, the future survival of $B$. compacta in Western Australia is in doubt because of climate change, which has already reduced rainfall in the south-west (CSIRO, 2005).

\section{Branchinella mcraeae Timms}

Branchinella mcraei Timms, 2005: 444-446, figures $2 b, 3,4$.

\section{Material examined}

Australia: Western Australia: 19 o, 26 q, Myanore Creek Pool (type locality), via Onslow,

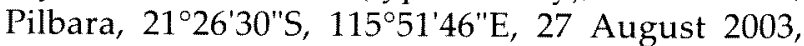
A. Pinder, J. McRae (WAM C34035-8); 3 oे, Edgina Creek scrape, via Port Hedland, Pilbara, 21 ${ }^{\circ} 31^{\prime} 38^{\prime \prime} \mathrm{S}, 118^{\circ} 45^{\prime} 09^{\prime \prime} \mathrm{E}, 26$ August 2003, A. Pinder, J. McRae (WAM C39199); 1 ơ 1 \%, DeGrey Claypan, via Port Hedland, Pilbara, $20^{\circ} 17^{\prime} 42^{\prime \prime S}$, $119^{\circ} 25^{\prime} 21^{\prime \prime} \mathrm{E}, 14$ August 2004, A. Pinder, J. McRae (DEC, Woodvale, voucher ANOS028B); 30 specimens, Curara Claypan, via Paraburdoo, Pilbara, 22 ${ }^{\circ} 39^{\prime} 50^{\prime \prime} S, 116^{\circ} 04^{\prime} 06^{\prime \prime} \mathrm{E}, 17$ August 2005, A. Pinder, J. McRae (DEC, Woodvale, PSW072); 5 $\$, 10 \&$ a creek pool off the NE Coastal Highway, via Port Hedland, Pilbara, $20^{\circ} 49^{\prime} 38^{\prime \prime} \mathrm{S}, 118^{\circ} 06^{\prime} 06^{\prime \prime} \mathrm{E}$, 5 August 2005, A. Pinder, J. McRae (WAM C39200). 


\section{Etymology}

The original species name is a noun in the genitive case, and hence should be female to reflect that it was named after a lady, Jane McRae. Therefore under Rule 31.1 .2 of the International Code for Zoological Nomenclature the name Branchinella moraei is emended to Branchinella mcraeae.

\section{Remarks}

When Branchinella mcraeae was described it was known only from the type locality, but subsequent collecting has found it to be widespread in the northern Pilbara. It typically lives in turbid to very turbid reddish waters of creek pools or claypans.

\section{Branchinella multidigitata sp. nov.} Figure 3

\section{Material examined}

\section{Holotype}

Australia: Western Australia: d, Well 48, Gregory's claypan, Canning Stock Route, 20 $15^{\prime}$ S, $126^{\circ} 31^{\prime} \mathrm{E}$, 9 December, 1971, M.H. Shepherd (WAM C38277). Length $9.9 \mathrm{~mm}$.

\section{Paratypes}

Australia: Western Australia: 1 o, 1 , plus many pieces of fairy shrimp collected with holotype (WAM C34492).

\section{Diagnosis}

Branchinella multidigitata differs from most species of Branchinella in that it has a forked frontal appendage with simple lateral branches, but so does $B$. basispina, $B$. dubia, $B$. pinnata, $B$. tyleri and $B$. wellardi. It is however unique in that there are about six lateral and three terminal subbranches, a few medial papillae on the two branches, no outgrowth in the fork of the two branches and no spine at the junction of the first and second antennomeres. Branchinella basispina, its closest morphological relative, has two basal spines on the frontal appendage trunk instead of six and it has medial subbranches; besides its second antennomere is not hooked terminally as in $B$. multidigitata. In the key to Branchinella species by Timms (2004) a new couplet is needed at 27 a to separate these two species. Branchinella pinnata is the next most similar species, but it has no basal spines, and many more lateral and terminal subbranches. Females of $B$. multidigitata are somewhat distinguishable (unusual for Branchinella - Timms, 2004) in that their antennae are rounded terminally instead of having an appendix or point there.

\section{Description}

Male

First antennae (Figure 3A) slightly longer than second antennal proximal antennomere, filiform and apex bevelled. Second antennal proximal antennomere (Figure 3B) partly fused and with distal half at about a $30^{\circ}$ angle to the body axis. Distal antennomere about same length as proximal, gently curving concavely and narrowing subapically. Apex short, abruptly bent medially 90 degrees. Numerous wéak transverse ridges along most of the medial surface.

Frontal appendage (Figure 3B) complex, about twice the length of the second antennae, with short trunk and two long branches. Proximal to the primary bifurcation, the trunk bears about five long lateral spines. Each branch with six lateral secondary branches at (or near) right angles to primary branch. Branch medial surface with two medial spines and three subapical short branches. Branch with three apical sub-branches. The lateral sub-branch of the apical set probably a continuation of the main axis of each branch and the other two, generally a little shorter than the apparent primary branch (but not always). All secondary branches with pairs of lateral spines and a terminal larger spine. The lateral spines of the terminal subset of secondary branches plus the extended primary branch about twice the size of the lateral spines of the lateral secondary branches.

The thoracopods were not examined due to the potential of the specimen for further disintegration.

Genital segments (Figure 3C) slightly expanded, terminating in two ventral, parallel gonopods. Everted gonopods proximally smooth, remainder with an incomplete lateral row of equilateral triangular spines and medial surface with a narrow, longitudinal field of longer, narrower spines. Gonopods extending to base of third abdominal segment, but it is possible the gonopods are not fully extended.

Cercopods about three abdominal segments long, with long lateral and medial setae.

\section{Female}

Size as in male. First antenna (Figure 3D) slightly longer than the second antenna. Both antennae about twice as long as eye plus eyestalk. Second antenna (Figure 3D) rectangular with rounded apices. No other features were able to be determined on the almost disintegrated specimen.

\section{Etymology}

The specific name refers to the large number (about 28) of branches on the frontal appendage, most with terminal and lateral spines. These branches are like having many fingers (=digits), each probably for touching the fomale before amplexus. 

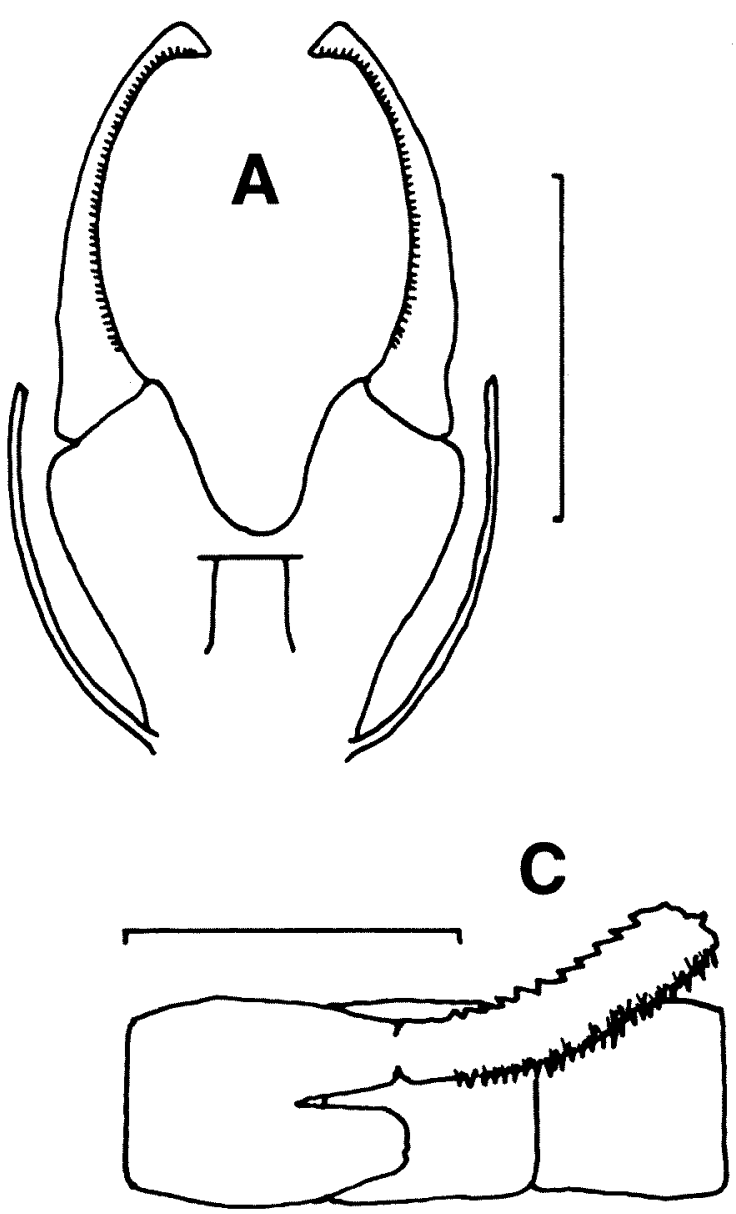

B

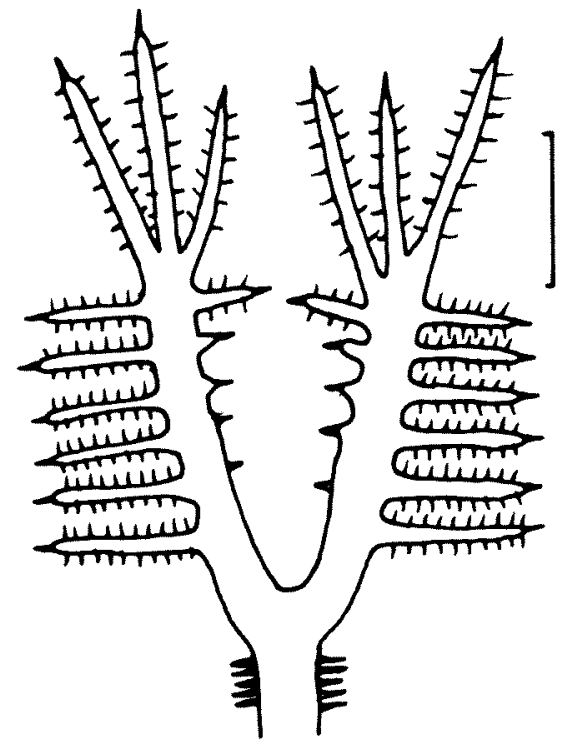

D

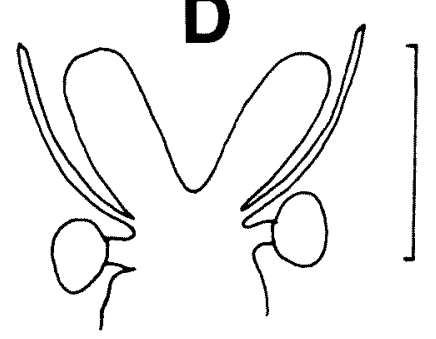

Figure 3 Branchinella multidigitata sp. nov.: A, dorsal view of male head; B, dorsal view of frontal appendage of male, branches and subbranches expanded; $C$, ventral view of male genital segments and adjacent abdominal segments with one gonopod everted; D, dorsal view of female head. Scale bars $1 \mathrm{~mm}$.

\section{Remarks}

Despite the paucity of material of this new species and its poor state of preservation, it is unlikely more will be collected in the near future, as the site is very remote (Figure 1) and rainfall in that area extremely episodic. Describing it now will aid in understanding the diversity of Branchinella and, in particular, add to the known amazing variation in structure of the frontal appendage of Branchinella males.

Morphologically the species is most similar to all Branchinella species with complexly branched frontal appendages, but in particluar $B$. pinnata Geddes, 1981 and to a lesser extent to $B$. frondosa. The frontal appendage of Branchinella multidigitata differs from that of $B$. pinnata, in that the latter (a) lacks the lateral spines on the frontal appendage trunk, (b) has seven lateral branches grading into about six terminal branches and hardly any medial branches, and (c) has far fewer spines on the secondary branches. Moreover, $B$. pinnata typically has a spine at the apex of the second antennal proximal antennomere (but not always - see below), whereas $B$. multidigitata does not, and the apex of the distal antennomere is not expanded in B. pinnata as it is in B. multidigitata. Branchinella frondosa also lacks an expanded apex of the distal segment of the second antenna, and more importantly its frontal appendage has some subbranches secondarily ramified, none on the medial side of the primary branch and fewer sub-branches overall (about 14).

Though the female is virtually undescribed, what is known is significant. The second antenna is unlike any other in Branchinella in that the apex is not pointed, nor is there a pointed appendix (see Timms 2004, figures 85-97). The general shape (excluding the pointed appendix) is reminiscent of the antenna of $B$. affinis; certainly it is unlike that in $B$. pinnata.

Branchinella multidigitata was collected from a very remote area of the state. Interestingly its close relative $B$. pinnata is known from the middle Northern Territory and also the Pilbara (as reported below), so it is possible $B$. multidigitata has speciated in isolation from $B$. pinnata. Alternatively its other close relative, $B$. frondosa occurs further south across the middle of Western Australia (see 
figure 4 in Timms, 2002) and this species could be an isolate from it.

\section{Branchinella papillata sp. nov. \\ Figures 4, 5A}

\section{Material examined}

\section{Holotype}

Australia: Western Australia: of, pond just east of the lake next to Kau Rock in the Kau Nature

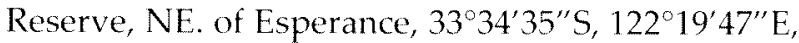
29 January 2007, B.V. Timms (WAM C38865).

\section{Allotype}

Australia: Western Australia: $q$, collected with holotype (WAM C38866), length $18.5 \mathrm{~mm}$.

\section{Paratypes}

Australia: Western Australia: $2 \delta$, collected with holotype, 15 and $16 \mathrm{~mm} ; 2$, collected with holotype, 16.2 and $17 \mathrm{~mm}$ (WAM C38867).
Other material

Australia: Western Australia: 2 \&, 2 , salt lake about $1 \mathrm{~km}$ east of Peak Charles, northwest of Esperance, 32 53'S, $121^{\circ} 11^{\prime} \mathrm{E}, 21$ January 2007, B.V. Timms (WAM C38868).

\section{Diagnosis}

Branchinella papillata is separable from those Branchinella lacking a frontal appendage $(B$. buchananensis, $B$. compacta, $B$. hattahensis, $B$. nana, $B$.nichollsi, $B$. simplex and $B$. vosperi), by having two sets of papillae medially on the basal antennomere, instead of a distinctive outgrowth (B. buchananensis, $B$. hattahensis, $B$. nichollsi, $B$. vosperi) or a completely smooth medial surface ( $B$. compacta, $B$. nana, $B$. simplex). An extra couplet between $5 b$ and 8 in the Branchinella key (Timms, 2004) is needed to distinguish this species. The female has its first antennal bases fused with the head and carried at right angles, and therefore is similar only to $B$. compacta and $B$. vosperi, but it is distinguishable from both of these species by the lack of genital outgrowths dorsally and/or laterally.
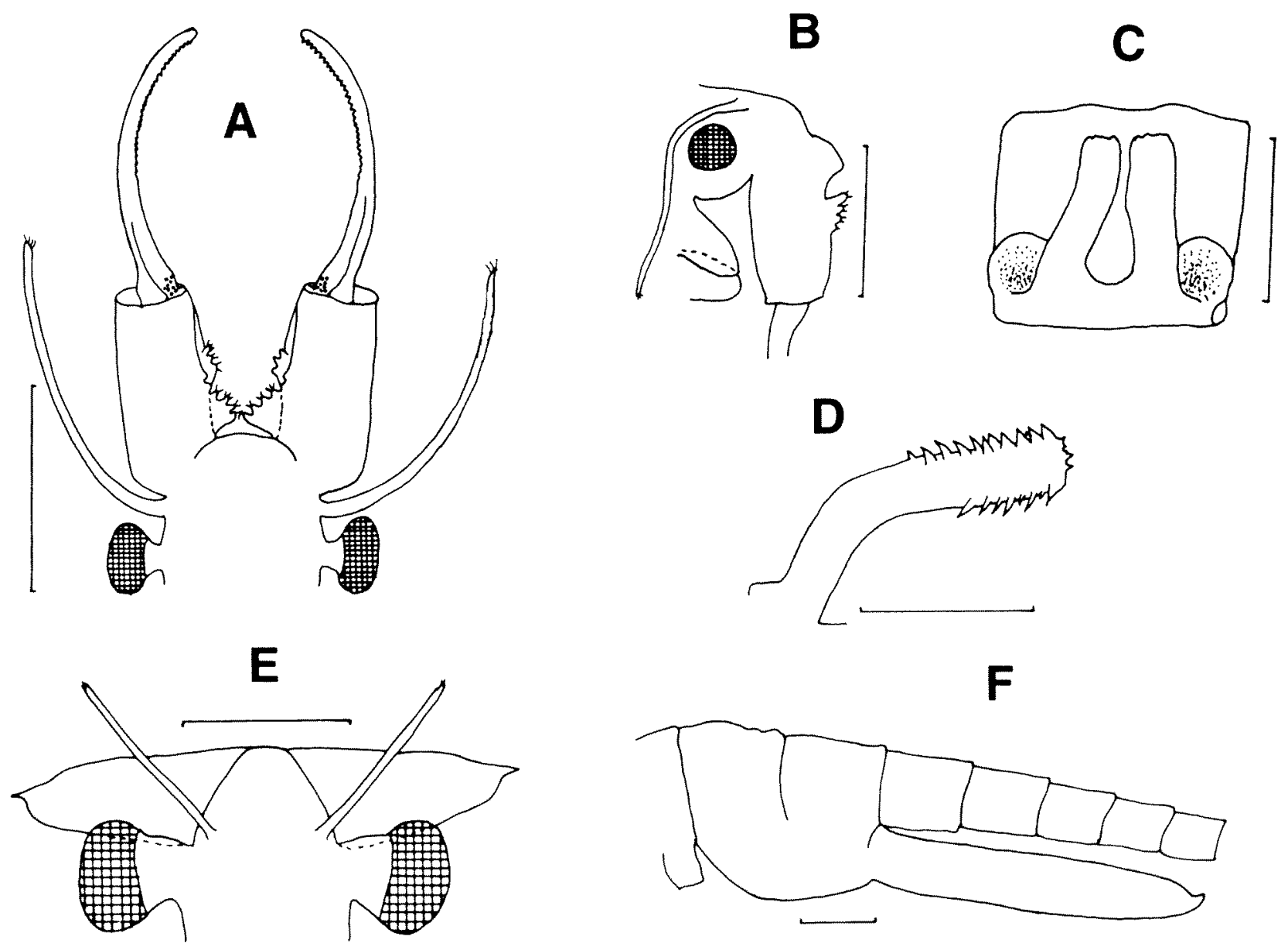

Figure 4 Branchinella papillata sp. nov: A, dorsal view of male head; B, lateral view of male head; $C$, ventral view of penes base; D, lateral view of a gonopod; E, female head; F, lateral view of female genital segments with brood pouch, and of five following abdominal segments. Scale bars $1 \mathrm{~mm}$. 


\section{Description}

Male

Length $15 \mathrm{~mm}$.

First antenna filiform (Figure 4A), a little longer than second proximal antennomere and apex bevelled with 3-4 long sensory setae. Second antenna (Figure $4 \mathrm{~A}$ ) with proximal segment fused at base but with remainder as two cylinders in axial alignment with body. Medial surface with a few adjacent papillae midway along the ventral surface, and with a series of largely coalesced papillae increasing in size basally on the anterioventral corner of each cylinder. All papillae with sparse short hair setae terminally. Adjacent area of clypeus humped with not even a vestige of a frontal appendage. Distal second antennomere a little longer than then the basal segment, curved and of even thickness except for some thickening basally. Medial surface with numerous transverse ridges, best developed apically and hardly apparent on basal third of segment. Medial surface at junction of the two segments roughened with chaotic minor ridges and hollows.

Gonopod bases (Figure 4C) well separated and each separated from a lateral lobe by a hollow. Gonopods normally inverted and less than one abdominal segment long, but when everted (as in a paratype) about 1.5 abdominal segments long. Everted gonopod of normal Branchinella type (Figure 4D) with a 1-3 uneven rows of backwardly directed triangular spines medially and also laterally. Both fields of spines crowded apically and confined to apical half of gonopod. Medial rows of spines tend to be more triangular and lateral row(s) more spikey.
Fifth thoracopod (Figure 5A) with endite $1+2$ and 3 evenly curved, the former about three times the size of the later. Anterior setae of endite 1 naked, anterior setae of endite 2 shorter, attended by a small seta basally and bearing a one-sided pectin of spines, and anterior setae of endite 3 the longest and also with a one-sided pectin of spines. Posterior setae long and numbering about 58 on endite $1+2$ and ca. 13 on endite 3 . Endites 4 to 6 asymmetrical and covered with small fine spines. Endites 4 to 6 each with one anterior seta and 6, 4 and 3 posterior setae respectively. Anterior setae of endites 4-6 short, and with untidy hairs basally and a minute pectin of hairs on the remaining two-thirds of their length. Endopodite elongated but broadly rounded apically and with a notch on apical margin much nearer the medial edge than the lateral edge. About 15 long posterior setae on medial edge of endopodite. Each of these setae with a coronet of small spines basally. Remainder of endopodite clothed with approximately 40 long posterior setae. Exopodite tear-drop shaped, protruding somewhat less than the endopodite and bearing about $50-60$ setae, longest apically, and absent basal medial edge. Epipodite oval and protruding less than the endopodite and praeepipodite. Praeepipodite subequal in size to the endopodite, and with a weakly serrated margin.

Cercopods fringed with setae and almost as long as last two abdominal segments plus the telson.

\section{Female}

Length $18.5 \mathrm{~mm}$. First antennae subequal in length to second antenna, filiform and terminating in a few setae on a bevelled surface. Second antenna
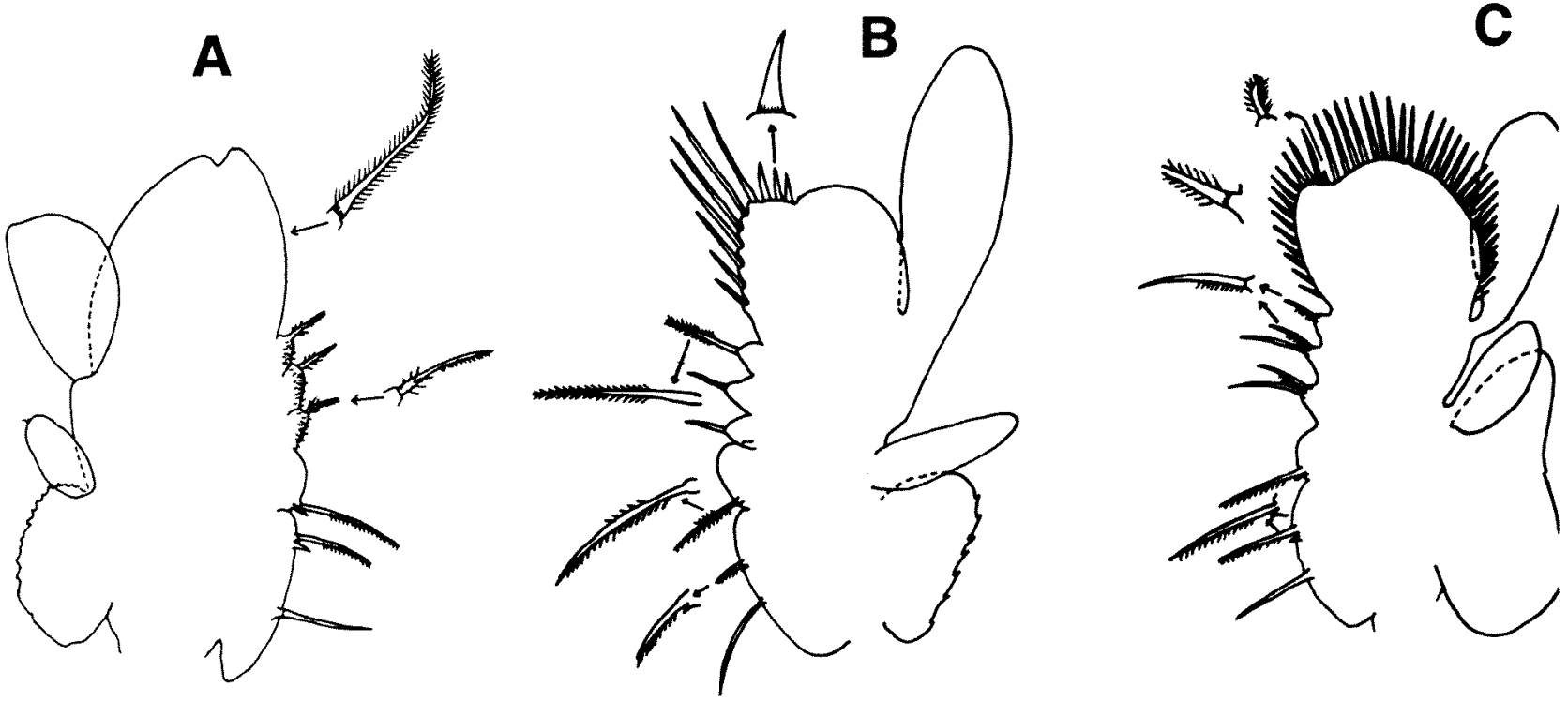

Figure 5 Male fifth thoracopods: A, Branchinella papillata sp. nov., B, Branchinella pinderi sp. nov. and C, Branchinella vosperi sp. nov. Note that most of the anterior setae are not shown, except for those on medial surface and notch of the endopodite of $B$. pinderi and except for the one on notch of the endopodite of $B$. vosperi. 
(Figure 4E) projecting laterally rather than anteriorly, with a wide base, lamellar and narrowing to an appendicular apex, so that its length is about twice its basal width. Anterior edge of lamellar plate more or less straight, but posterior edge with a marked shoulder near the apex.

Genital segments (Figure 4F) smooth (although there may be wrinkles due to body flexing) and bearing a simple brood pouch with a tubular extension almost five abdominal segments long.

Fifth thoracopod and cercopods as in male.

\section{Etymology}

The specific name refers to the numerous papillae on the medial surface of the basal antennal segment. This is the only known species of Branchinella to have such features.

\section{Remarks}

Males of this species are distinctive by a complete absence of a frontal appendage and the presence of coalesced papillae on the medial surface of the basal antennomere. Even the females are unusual among Branchinella species by having a short lamellar second antenna and a particularly long brood pouch. This species clearly belongs to Group I of Geddes (1981) with its robust body, lack of (or weakly developed) frontal appendage, elongated endopodite, and the females having lamellar second antennae (Geddes, 1981; Timms, 2004). It is most similar to $B$. vosperi, but in males it is distinguished by papillae on the medial ventral edge of the free cylindrical part of the basal segment of the second antenna, whereas in $B$. vosperi there is a filamentous outgrowth midway along this medial surface. In females, the first and second antennae are of subequal lengths in $B$. papilla but in $B$. vosperi the second antenna is much longer than the first. Moreover the genital segment of $B$. vosperi has various outgrowths, compared to the usual smooth surface in this species.

Brachinella papillata is known from two lakes in the Esperance hinterland. Both are generally saline (to at least $50 \mathrm{~g} / \mathrm{L}$ ), but this species occurs in the early stages of filling when the lakes are hyposaline (13 $\mathrm{g} / \mathrm{L}$ in the case of the Peak Charles lake and $14 \mathrm{~g} /$ $L$ in the case of the Kau Reserve pond).

\section{Branchinella pinderisp. nov}

Figures 5B, 6

\section{Material examined}

\section{Holotype}

Australia: Western Australia: d, from a very turbid (8200 NTU) unnamed claypan on Minderoo Station, via Onslow, Pilbara, 21054'59"S, $114^{\circ} 54^{\prime 32}$ E, 17 May 2005, A. Pinder, J. McRae (WAM C38278), length $7.8 \mathrm{~mm}$.
Allotype

Australia: Western Australia: 9 , collected with holotype (WAM C38279), length $14.6 \mathrm{~mm}$.

\section{Paratypes}

Australia: Western Australia: 3 8, collected with holotype, $8.5,8.0$ and $7.5 \mathrm{~mm}, 29$, collected with holotype, 14 and $14.9 \mathrm{~mm}$ (WAM C38280).

\section{Diagnosis}

Branchinella pinderi has a forked lamellate frontal appendage and so is grouped with $B$. budjiti, $B$. campbelli, B. complexidigidata, B. kadjikadji and $B$. lamellata. It is distinguished from these five species by having three simple lateral branches on the trunk of the frontal appendage and a simple rhomboidal lamellate branch instead of various elaborate lamellates. An extra couplet is needed in the Branchinella key (Timms, 2004) between $28 \mathrm{~b}$ and 30 to separate this species. Females are distinguishable from all other species of Branchinella by having the first antennae about twice as long as the second antennae and by its very small eye.

\section{Description}

Male

Length of mature individuals known to vary between 7.5 and $8.5 \mathrm{~mm}$

Eyes small (Figure 6A), about the diameter of the expanded apices of the second antennal distal antennomere and on stalks about the same length as the eye itself. First antennae (Figure 6A) filiform, about a third longer than second antennal proximal antennomere, and apex bevelled with 3-4 long sensory setae.

Second antennal proximal antennomeres (Figure 6A) partly fused and with free distal part in line with body axis. Apex about twice as wide as base of distal antennomere, with a distolateral protuberance, and with many (ca. 6-12) filiform setae distally near base of distal antennomere and on proximolateral surface. Distomedial surface with a large pulvillus with numerous denticles.

Second antennal distal antennomeres (Figure 6A) almost twice as long as proximal antennomeres, slightly arcuate medially, each with a basomedial knob-like protuberance and an expanded rounded apex. Medial surface with numerous weak transverse ridges.

Frontal appendage (Figure 6A) large, with a short trunk and two primary branches about three times the trunk length. Stem pseudosegmented and with three ventrolateral digitform processes. Digitform process length subequal to trunk width and terminating in a spinulated bulb with a large, terminal spine (Figure 6C). Trunk bifurcation with mediodorsal thickened granular area. Primary branches narrow rhomboidal, lamellar and bearing 

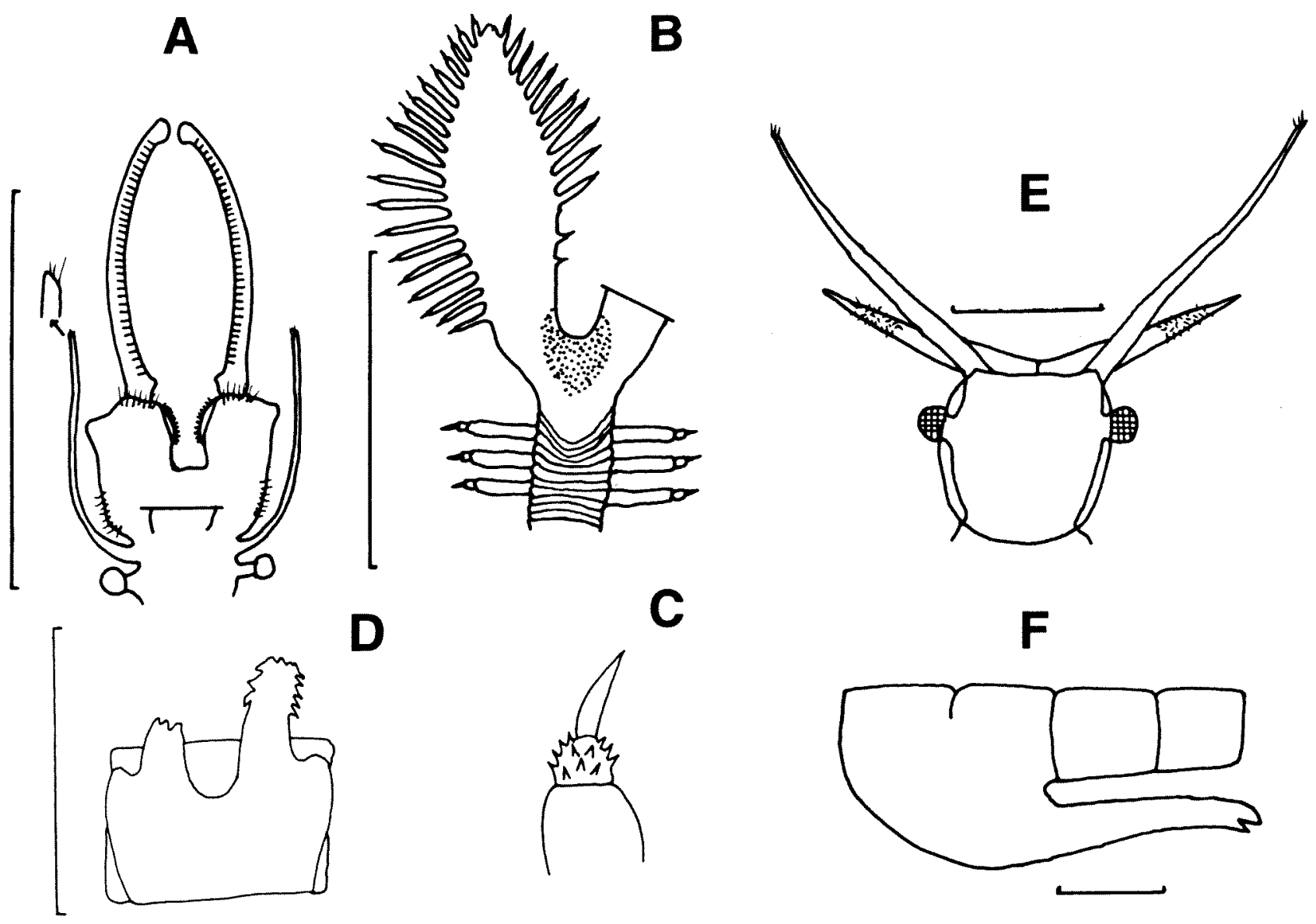

Figure 6 Branchinella pinderi sp. nov.: A, dorsal view of male head; B, dorsal view of frontal appendage of male; C, enlarged view of terminal bulb and spine on a stem digit; $D$, ventral view of penes base and gonopods; $E$, dorsal view of female head; F lateral view of female genital segments with brood pouch, and of adjacent two abdominal segments. Scale bars $1 \mathrm{~mm}$.

about twenty lateral, narrow digitiform papillae, graded in length with longest midway along branch. Medial margin of branch with about 13 digitiform papillae, with the longest distal of widest part of branch and last two very short. Each digitiform papillae terminating similarly as in the trunk digitiform processes, but bulb and spines smaller.

Gonopod bases (Figure 6D) well separated and each with a lateral lobe, the whole structure just narrower than the genital segment. The gonopods partly everted on a paratype with a row of long sharp spines laterally and triangular spines medially.

Fifth thoracopod (Figure 5B) with endite $1+2$ and 3 evenly curved, the former about three times the size of the later. Anterior setae of endite 1 naked, anterior setae of endite 2 short, attended by a small seta basally, bearing a one-sided pectin of spines, and anterior seta of endite 3 long and with a long pectin of setae on one side and a short pectin midlength on the other. Posterior setae long and numbering about 55 on endite $1+2$ and 15 on endite 3 . Endites 4 to 6 asymmetrical and covered with small fine spines. Endites 4-6 each with one anterior seta and 3, 2 and 2 posterior setae respectively. Anterior setae of endites 4 and 5 short and naked, and that of endite longer and feathered. Endopodite broadly rounded with a notch on apical margin much nearer the medial edge than the lateral edge. About 7 long posterior setae on medial edge of endopodite and 3 stout setae medially to the notch. These setae with a coronet of many very small spines basally. Remainder of endopodite clothed with about 18-20 long setae. Exopodite elongated oval, protruding about the length of the endopodite and bearing 30-35 setae. Epipodite sausage shaped, but apex bluntly pointed. Praeepipodite somewhat smaller than the endopodite, with rounded distal and proximal corners and a weakly serrated, almost straight edge in between.

Cercopods fringed with setae and almost as long as three abdominal segments.

\section{Fenale}

Mature length 14-15 mm, much bigger than males. Head (Figure 6E) with a dorsolateral carina. Eyes small, length less than basal width of either antennae, and on an even shorter peduncle. Both 
eyes almost obscured under head dorsolateral carina. First antennae about twice as long as second antenna, filiform and terminating in a few setae on a bevelled surface. Second antenna joined basally and about as wide as base of first antennae, but narrowing to a filiform apex. Apical third, exclusive of filiform apex, with many fine setae dorsally.

Genital segments (Figure 6F) smooth and bearing a simple brood pouch extending posteriorly to base of third abdominal segment.

\section{Etymology}

The specific name honours Adrian Pinder, scientist from the Western Australian Department of Environment and Conservation, who has been instrumental in collecting many specimens of large branchiopods in Western Australia.

\section{Remarks}

This species belongs to the genus Branchinella by reason of its gonopod structure (Geddes, 1981; Rogers, 2006). The adult size, nature of the frontal appendage, presence of swellings lateral to the gonopods, and features on the thoracopods suggests it belongs to Group II of Geddes (1981), but it is difficult to find a near relative. The numerous digitiform processes on the frontal appendage with their terminal spines suggest a Group III alliance, but this is the only feature shared with this group (Geddes, 1981). The nearest similar frontal appendage structure is that of $B$. kadjikadji with its numerous digitiform processes on lamelliform branches (Timms, 2002), but overall shapes, digitiform process types and numbers and terminal spines are very different. Branchinella pinderi is easily distinguished from $B$. mcraeae, the other anostracan in turbid waters of the Pilbara, by its very different frontal appendage, which in $B$. mcraae has a long trunk dividing into two short branches each with a tapering apex (Timms, 2005). In B. pinderi the knobs on the bases of the distal antennomere of the second antennae are similar to the basal spines of B. nana (Timms, 2002), but that is the only feature shared with this species. Many species (e.g. B. compacta, B. halsei, B. probiscida, $B$. clandestina Timms, 2005) have denticulate pulvilli on the second antennal proximal antennomere medial surface, but none like that in $B$. pinderi. The hair setae at two sites on this proximal antennomere appear to be unique to $B$. pinderi, and this species has the greatest discrepancy between the distal diameter of the basal antennomere and proximal diameter of the distal antennomere. Of final note, are some apparent adaptations to the extreme turbidity of its habitat: in keeping with the reduced importance of light, the eye is relatively small and both sexes have fine appendages to facilitate touching - excessive branching of the frontal appendage in the male and the long antennules in the female.

\section{Branchinella sp. near pinnata Geddes Figure 7}

Branchinella pinnata Geddes, 1981: 278-281, figs. 13, 14; Timms and Geddes: 2003, 64.

\section{Material examined}

Australia: Western Australia: 1 mature 6 , Myanore Creek Pool, Pilbara, 21 29.6"S, 115 46.5"E, 27 August 2003, J. McRae, A. Pinder (WAM C38281). This is site PSW014 of DEC's Pilbara study (S. Halse, pers, comm.).

\section{Remarks}

This is the first record of this species in Western Australia (Figure 1). There are numerous records of this species from the middle Northern Territory, inland Queensland, and north-western New South Wales (Geddes, 1981; Timms and Sanders, 2002; Timms and Geddes, 2003). Although the single male in the collection accords with most aspects of the original description of $B$. pinnata, it differs in three features, two of which Geddes (1981) thought important. It lacks the dorsolateral spine at the apex of the second antennal proximal antennomere and lacks the 6-8 swellings at the base of the setae on the mediodistal corner of the endopodite (= distal endite of Geddes, 1981) on the middle thoracopods (cf. Figure 7A with Figure 14b in Geddes, 1981). The other distinguishing feature is on the distal medial surface of the free part of the second antennal proximal antennomere, which is sclerotized and raised into two transverse ridges (Figure 7B). Also, both this male and one of the paratypes, but not the holotype, have a soft lobe apically on the medioventral surface on the basal antennomere (Figure 7 C, D), a feature not reported by Geddes (1981).

Until more specimens, including females, from the Pilbara are studied, it is appropriate to consider this male a variant of $B$. pinnata, rather than a separate species.

\section{Branchinella vosperi sp. nov.} Figures $5 \mathrm{C}, 8$

\section{Material examined}

\section{Holotype}

Australia: Western Australia: $\delta$, from road ruts on Mt Ney Track in Kau Nature Reserve, about 60 $\mathrm{km} \mathrm{NE}$. of Esperance, $33^{\circ} 28^{\prime} \mathrm{S}, 12221 \mathrm{E}, 3$ August 2005, B.V. Timms, J. Vosper (WAM C38282), length $20 \mathrm{~mm}$. 

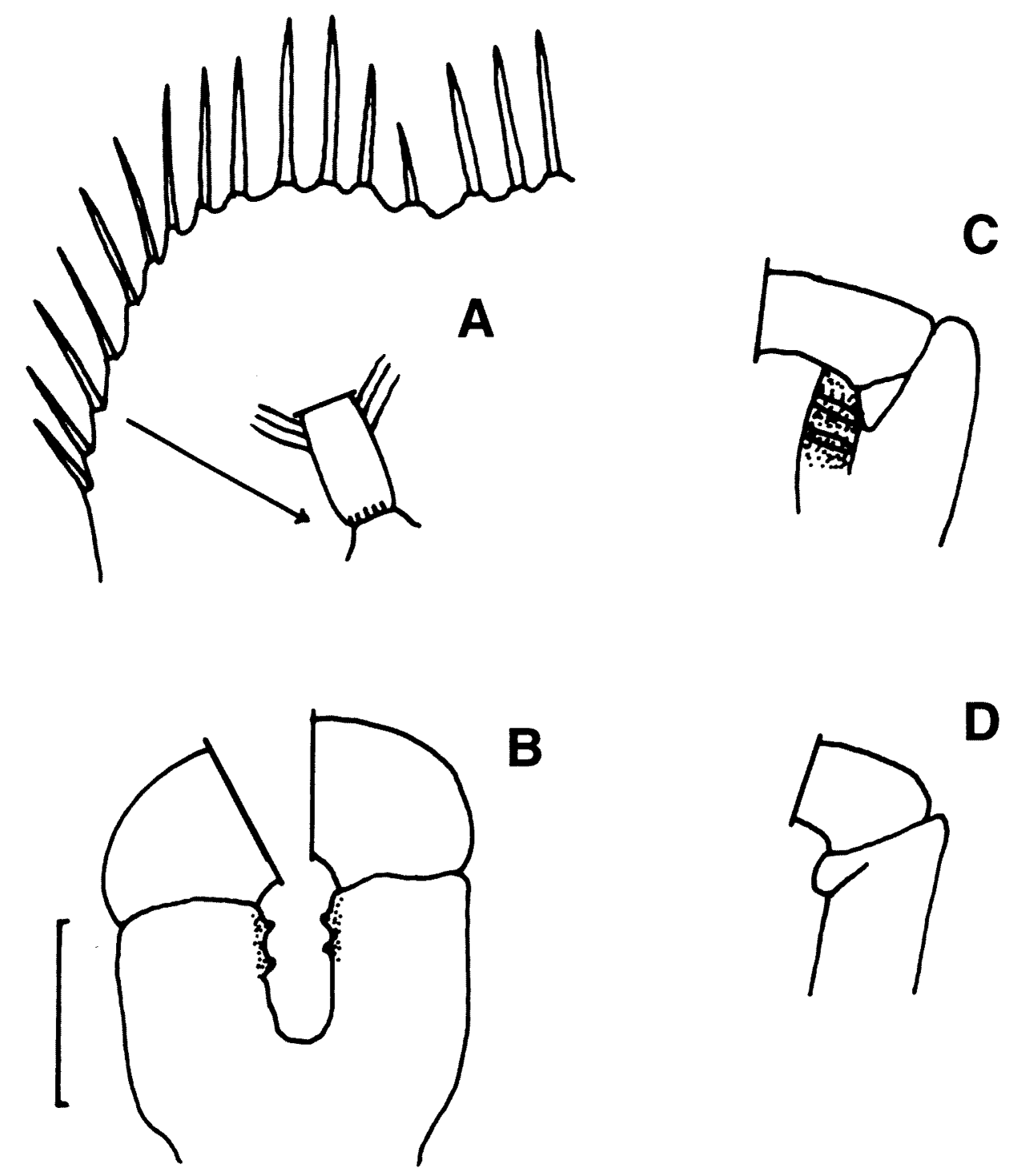

Figure 7 Branchinella pinnata Geddes, from the Pilbara district, Western Australia: A, distomedial corner of endopodite showing lack of swellings at base of setae (cf, Figure 14b in Geddes, 1981); B, chitinization and ridges on medial face of basal segment of second antenna, dorsal view; $C$, medioventral view of the chitinized ridges and outgrowth at junction of basal and distal segment of second antenna; D, ventral view of the outgrowth at the junction of basal and distal segment of second antenna. Scale bar $1 \mathrm{~mm}$.

Allotype

Australia: Western Australia: $q$, collected with holotype (WAM C38283), length $23 \mathrm{~mm}$.

\section{Paratypes}

Australia: Western Australia: 2 \&, collected with holotype (WAM C38284), 17 and $18.5 \mathrm{~mm} ; 2$ ㅇ. collected with holotype, 20 and $24 \mathrm{~mm}$ (WAM C38284); 2 o, collected with holotype, 15 and 16 $\mathrm{mm}, 2$ \&, 16 and $25 \mathrm{~mm}$ (AM P74347).

\section{Other material}

Australia: Western Australia: 2 o, 8 , same location as holotype, 30 January 2007, B.V. Timms (BVT private collection).

\section{Diagnosis}

Like $B$. buchananensis, $B$. compacta, $B$. hattahensis, $B$. nana, $B$. nichollsi, $B$. papillata and $B$. simplex, $B$. vosperi lacks a frontal appendage, thus separating it from most species of Branchinella. It is separable from these seven species by being the only one with an outgrowth midway on the medial surface of the basal antennomere. A further distinguishing feature from these species is the presence of a prominent ventrolateral acute projection on the base of the distal antennomere. In the Branchinella key (Timms, 2004), couplet 5 needs to be modified and an extra couplet instead between 5 and 6 . Like other females of this group of Branchinella, the first antenna are strap-like, fused basally and held 

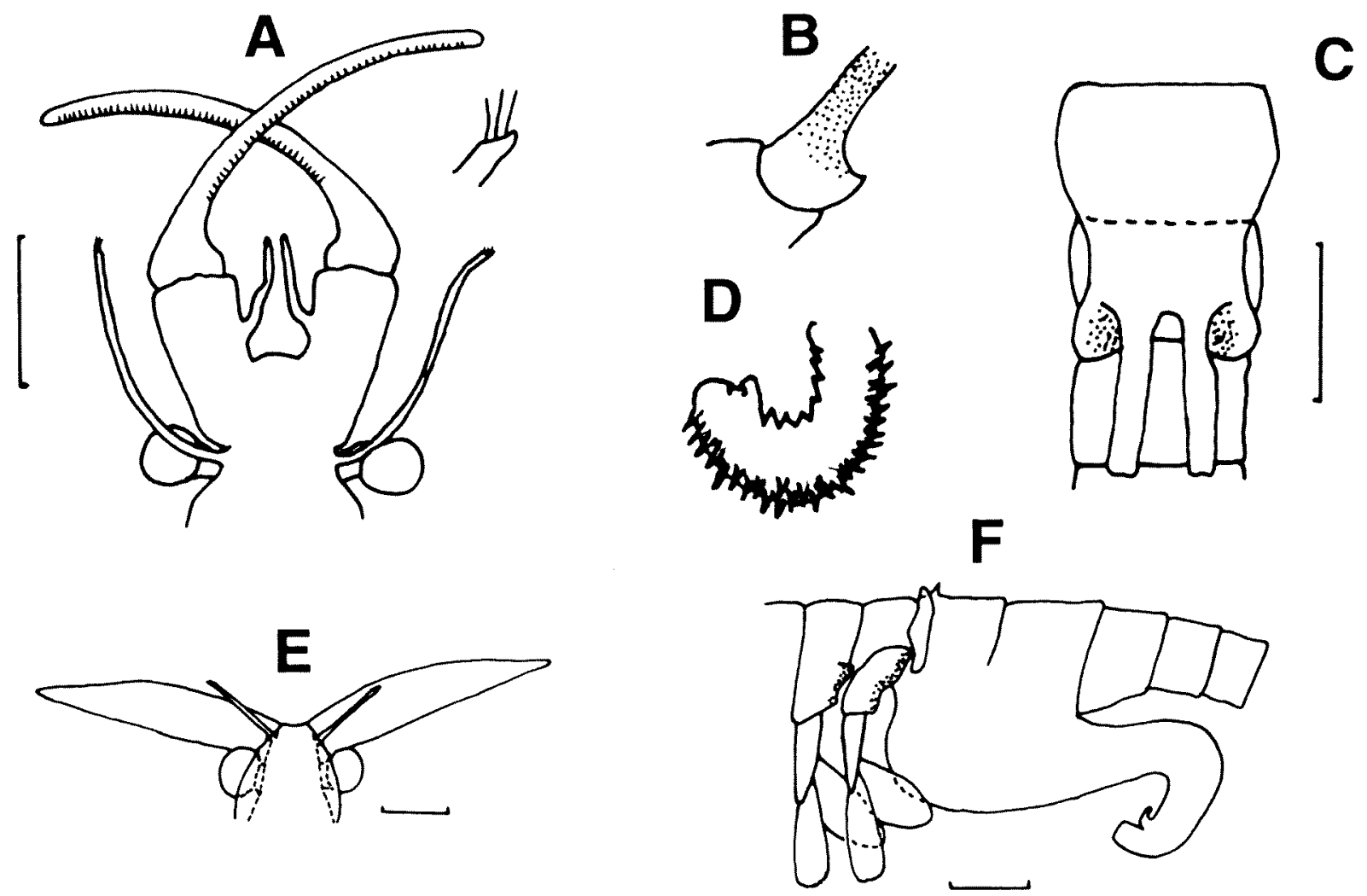

Figure 8 Branchinella vosperi sp. nov. A, dorsal view of male head; B, ventrolateral view of base of distal segment of second antenna; $C$, ventral view of male genital segments and adjacent abdominal segments; $D$, distal part of a gonopod; E, dorsal view of female head; F, lateral view of female genital segments with brood pouch, and of adjacent thoracic segment and abdominal segments. Scale bars $1 \mathrm{~mm}$.

at right angles, and similarly to $B$. compacta there are outgrowths on the genital segments, but only $B$. vosperi has outgrowths on the last two abdominal segments.

\section{Description}

Male

Length of mature individuals known to vary between 15 and $20 \mathrm{~mm}$.

Eyes freely projecting on stalks shorter than the diameter of the eye (Figure 8A). First antennae filiform, slightly longer than second antennal proximal antennomere, with apex bevelled bearing 3-4 long sensory setae.

Second antennal proximal antennomere (Figure $8 \mathrm{~A})$ partly fused and with distal half diverging about $20^{\circ}$ from body axis. Medial surface with an unadorned filiform antennal appendage about the length of the free half of the basal antennomere. Second antennal distal antennomere about twice as long as proximal antennomere, slightly arcuate, narrowing gently apically. Medial surface with weak transverse ridges except at base and apex. Distal antennomere base thick, with a prominent ventrolateral acute projection (Figure 8B). Fontal appendage absent.
Fifth thoracopod (Figure 5C) with endite $1+2$ and 3 evenly curved, the former about three times the size of the later. Anterior seta of endite 1 smooth, and anterior setae of endites 2 and 3 with a pecten of fine spines and an attending small basal spine. Posterior setae long and numbering about 35-40 on endite $1+2$ and 11-12 on endite 3 . Endites 4 to 6 asymmetrical and covered with small fine spines. Endite 4 with 2 anterior setae and 3 posterior setae, endite 5 with 2 and 2 respectively and endite 6 with 1 and 2 respectively. Second anterior setae of endites 4 and 5 and the lone one of endite 6 with a row of fine spines on basal half. Endopodite broadly rounded with a notch on apical margin much nearer the medial edge than the lateral edge. Notch with a small bent seta covered with fine spines. Endopodite bearing about posterior 45 setae, each with about $8-10$ very small spines at its base, and with about almost a third of the setae on the medial edge before the small seta in the notch. Exopodite elongated oval but only a little longer than the endopodite and also with about 45 setae. Epipodite the same shape as the exopodite, but only half its size. Praeepipodite large (about equal to the endopodite plus epipodite) with rounded distal and proximal margins.

First genital segment (Figure 8C) expanded, 
second segment slightly narrower anteriorly, but expanded again posteriorly. Second genital segment with a hollow, lateral to each gonopods base. Gonopod base a simple tube. Gonopods not everted in holotype and only slightly so in one of the paratypes (WAM C38284); everted portion a row of triangular spines on one side and a narrow field of longer, narrow spines on the other (Figure 8D).

Cercopods about three abdominal segments long, and with long lateral and medial setae.

\section{Fente}

Head (Figure 8E) with an anteriolateral flange. Eyes on very short stalks and partly covered by anterolateral flange. First antennae filiform and about twice length of eye plus stalk. Second antennae lamellar, more or less at right angles to the head, capable of extending back to the second thoracic segment. Second antenna widest about one third of its length and narrowing evenly thereafter to a blunt apex.

Thoracopod five as in the male, but the eleventh thoracopod is smaller (about two-thirds size of T5) and with a reduced praeepipodite (about half normal size).

Brood pouch (Figure 8F) extending to the fourth to fifth abdominal segment, though usually in death it is recurved anteriorly. First genital segment with a chitinised dorsolateral spine projecting dorsally. Lateral to the spine, a prominent transverse ridge, projecting about twice as much as the spine and twice its width at the base. Eleventh abdominal segment with a large outgrowth ventrolaterally that is ridged on its posterior edge and touching the lower part of the lateral ridge on the first genital segment. Tenth abdominal segment with a lesser outgrowth ventrolaterally, touching that of the eleventh segment and slightly ridged posteriorly.

Cercopods as in male.

\section{Etymology}

The specific name honours John Vosper who has been the author's colleague on many adventures to the Outback lakes and pools.

\section{Remarks}

This species belongs to the genus Branchinella, by reason of the structure of the gonopods and brood pouch. It is a member of Group I of the genus (Geddes, 1981), i.e. it is similar to larger robust species such as Branchinella australiensis, $B$. compacta, $B$. simplex and the $B$. nichollsi group (Timms, 2005). Branchinella vosperi differs from all of these, however, by the male having a mesal filiform antennal appendage on the medial surface of the second antennal proximal antennomere, and the female has outgrowths on the last three thoracic segments. Almost certainly these outgrowths play an important role in species discrimination in amplexus (Rogers, 2002). It shares with its most closely related species, $B$. compacta, a complete lack of a frontal appendage, lateral hollows adjacent to the gonopods, similar female second antenna and amplexial grooves. This last character is unique to these two species among the genus Branchinella. Branchinella simplex is also similar, given its lack of a frontal appendage, simply constricted male second antenna, and similar female second antennae, but $B$. vosperi differs by the two unique characters mention above, together with shorter first antenna in $B$. vosperi, the presence of a hollow lateral to the gonopods and lateral process of the genital segments, and the female second antenna in $B$. vosperi is larger and tapers unevenly apically whereas in $B$. simplex it is smaller and tapers evenly apically. Though it shares some characters with the $B$. nichollsi group (namely lack of a frontal appendage, and basal hollows lateral to the gonopods base), $B$. vosperi is different by reason of its filiform antennal appendages, exopodite longer than endopodite in the thoracopods, and female second antenna narrowing unevenly to a sharp apex. Branchinella australiensis is even further removed from $B$. vosperi, as males of the former has a frontal appendage, females have a much longer second antenna, and in the thoracopods the endopodite is much larger than the exopodite.

Branchinella vosperi is known from only two road ruts with turbid waters in adjacent dune swales in the Kau Nature Reserve, northeast of Esperance, WA (Figure 1). It seems to have a relatively short life cycle, as adults were collected within a month of heavy rains, but four weeks later none could be found. It has been found in both summer and winter, indicating no seasonal preferences. No other anostracans shared these pools, though on the second collecting occasion, the clam shrimp Caenestheriella packardi was found in the pools.

\section{Branchinella wellardi Milner Figure 9}

Branchinella wellardi Milner, 1929: 29-31, plate 6; Linder, 1941: 269; Geddes, 1981: 281, figure 16f; Timms, 2002: 87.

\section{Material examined}

Australia: Western Australia: 5 \&, 5 q, large shallow pool near base of south side of Walga Rock, via Cue, $27^{\circ} 24^{\prime} \mathrm{S}, 117^{\circ} 28^{\prime} \mathrm{E}, 7$ August 2004 , B.V. Timms (WAM C38285); New South Wales: $2 \delta$, Marsilea Pool, Bloodwood Station, $130 \mathrm{~km}$ northwest of Bourke, 293' S, 144 $52^{\prime} \mathrm{E}, 31$ May 1999, B.V. Timms (AM P74346).

\section{Remarks}

This species is known from only a few sites in Western Australia in the Carnarvon and upper 

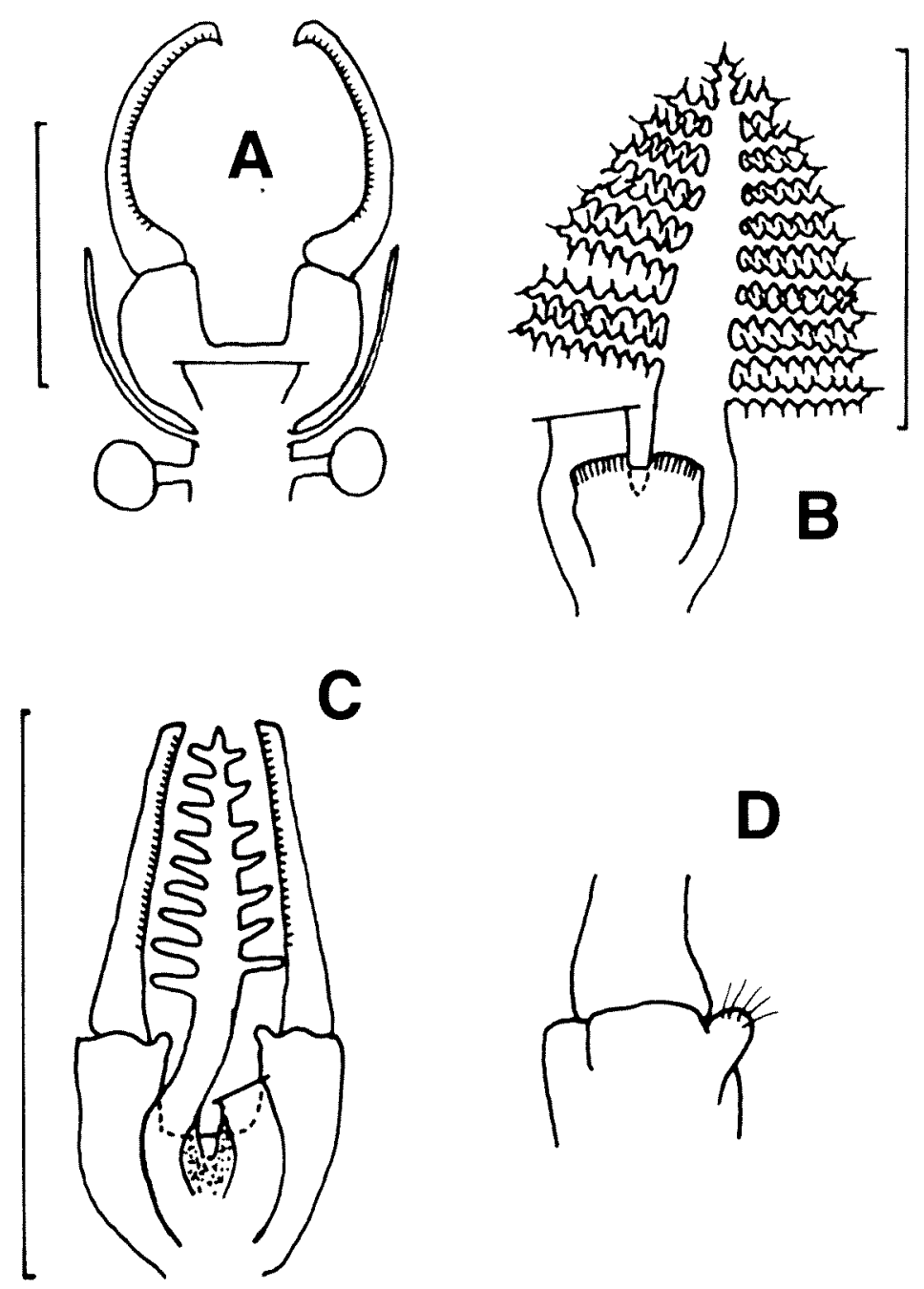

Figure 9 Branchinella wellardi Milner: $A$, dorsal view of a mature male head; $B$, dorsal view of the frontal appendage of a mature male; $C$, dorsal view of the head of an immature male; $D$, dorsal view of outgrowth at the junction of the two segments of the second antenna. A and B based on specimens (AM P74346) from Marsilea Pond, Bloodwood Station, NW New South Wales; C and D based on specimens from a pool at the base of Walga Rock, via Cue, Western Australia (WAM C38285). Scale bars $1 \mathrm{~mm}$.

Murchison areas (Milner, 1929; Timms, 2002), and also from a few sites in the middle Paroo basin in northwestern New South Wales and south-western Queensland (Timms and Sanders, 2002). The material Milner used in its description is lodged in the WAM (C12460), but it is poorly preserved and of little use (Geddes, 1981), but nevertheless should be considered as syntypes. Milner's description is adequate, but no modern illustrations exist. The figure of the frontal appendage in Geddes (1981) is simplified and contains an error, and Timms (2004) copied this drawing. Mature specimens from Marsilea Pond have the bilobed flat outgrowth at the junction of the trunk and branches of the frontal appendage overriding the base of the branches (Figure 9B), not between them as shown in Geddes (1981) and Timms (2004). The juveniles from the pool near Walga Rock (Figure 8C) lack this outgrowth, but have the medial parts of the junction area thickened, perhaps in anticipation for future development of the outgrowth. When mature these outgrow ths are fluted, unlike similar outgrowths in $B$. arborea and B. tyleri. These same juveniles have a partly developed frontal appendage, which lacks any spines, though it does have the correct number of secondary branches (9 laterally and 7 medially).

There are minor differences between western and eastern populations of $B$. wellardi. Western specimens have a lobed outgrowth with a few sensory setae on the mediodistal corner of the second antennal proximal antennomere (Figure 9a in Milner, 1929; Figure 9D), whereas eastern specimens lack this outgrowth (Figure 9A). Not surprisingly morphology of the second antenna and its frontal appendage changes as the animal develops. This is seen particularly in the shape of the distal antennomere, and in the relative growth of the outgrowths between the base of the frontal 
appendage branches (see above), and in the spination of the secondary branches (juveniles in Figure $9 \mathrm{C}$ lack terminal and lateral spines).

The new record at Walga Rock (Figure 1) does not significantly increase the known distribution of $B$. wellardi in Western Australia, but it is from a typical clear water habitat instead of the moderately turbid ones in the Carnarvon area (see Timms, 2002).

\section{NEW DISTRIBUTION RECORDS}

In a sampling program throughout the Wheatbelt, Goldfields and adjacent areas from 2003 to early 2006 (Table 1), 95 sites had at least one species of Branchinella, though six of these yielded two species, and another six shared the habitat with Streptocephalus sp. or Parartemia spp. Gnammas on rock outcrops were targeted, so that the most common species encountered was the rock pool specialist, Branchinella longirostris. It occurs throughout much of the eastern and northern Wheatbelt and adjacent Goldfields in an area a little larger than shown in Figure 5 in Timms (2002) and discussed in Timms (2007). Branchinella affinis was the most common species in habitats other than rock pools, confirming its status as the most common fairy shrimp in fresh waters in Western Australia (Timms, 2002). Occasionally it was also found in rock pools [as at Dunn Rock, Emu Rock (Figure 1)], should these be at the level of the adjacent countryside (Timms, 2007). The next most widespread species is $B$. australiensis, probably the most common species across much of Australia. Its new sites are within the distribution area shown in Figure 4 in Timms (2002).

Of the moderately common species, Branchinella halsei occurred most commonly in the central inland [e.g. some wetlands near Lake Carey (Figure 1)], but with one record at Lake Cronin (east of Hyden) (Figure 1) in the south, thus enlarging its known distribution shown in Figure 3 in Timms (2002). Almost all new sites for $B$. frondosa are around Lake Carey (Figure 1) so extending the known distribution a little to the southeast (see Figure 4 in Timms, 2002). The four new sites for $B$. occidentalis are within its known distribution, but those of $B$. proboscida at Lake Carey (Figure 1) extend the distribution of this species from coastal Carnarvon (Timms, 2002) to include the northern Goldfields. Both of these species prefer turbid claypans, so study of these habitats elsewhere could well encounter these species. The occurrence of $B$. simplex in saline waters of Lake Carey (Figure 1) spreads its known distribution a little and raises its known upper field salinity tolerance to $62 \mathrm{gL}^{-1}$ (Timms et al. 2007).
Five species were found once or twice. Branchinella denticulata was found twice in Lake Carey wetlands, within its known distribution (see Figure 5 in Timms, 2002). Branchinella kadjikadji occurred in adjacent claypans near the Cowcowing Lakes (Figure 1), north of Wyalkatchem, about 240 $\mathrm{km}$ southeast of its type locality near Morawa. As already noted in Timms et al. (2007), B. nichollsi was found in a freshwater wetland near Lake Carey (Figure 1), so enlarging its distribution northwards (see Figure 9 in Timms, 2002). The new record for $B$. wellardi and type locality for $B$. vosperi have been mentioned earlier.

\section{DISCUSSION}

The six species added to the state's fauna in this study all occurred at one or two sites each and, except for $B$. compacta, in small numbers. This exemplifies the difficulty of cataloguing the large branchiopods in Western Australia - many species occur in limited areas and then only haphazardly and few individuals are collected. Some seem to be particularly elusive. Branchinella apophysata from Mt Margaret near Lake Carey has still not been seen since its original description in 1941, despite the author and /or colleagues visiting the area six times over three years when water was known to be present. This study confirms that most species of Branchinella in Western Australia are uncommon, and the other end of the scale, that by far the most encountered species are $B$. Iongirostris and $B$. affinis (Timms, 2002).

The increase in the state's known fauna of Branchinella to 25 species, confirms Western Australia as an anostracan biodiversity 'hotspot' (Belk, 1998; Timms, 2002). With about 15 species, the same applies to Parartemia (A. Savage, pers comm.; author, unpublished data), and indeed to many other inland aquatic fauna (e.g. Coxiella and some ostracods (Pinder et al. 2002; Chydoridae, R. Sheil, pers. comm.; Daphniopsis Hebert and Wilson, 2000). In the case of Branchinella, diversity is promoted by the large latitudinal coverage of the state (three of the additional species were found in the far north and three in the far south). It is scarcely increased by niche partitioning, evidenced again in this study, as in Timms (2002), of only a few instances of congeneric occurrences.

Three of the four new species, although distinctive, are closely related to relatively common and widespread species. Branchinella multidigitata is similar to $B$. pinnata and to a lesser extent to $B$. frondosa, all members so Type III of Geddes (1981). Branchinella papillata and $B$. vosperi are similar to $B$. compacta, a Type I species. Branchinella pinderi has no obvious relative, though it somewhat similar to $B$. kadjikadji. It is conceivable that all four have speciated in isolation from their relatives, 
particularly so in the case of $B$. multidigitata surrounded as it is by extensive deserts with few waterholes, and known populations of its relative $B$. pinnata both east and west of the type locality.

Three of the additional species ( $B$. pinderi, $B$. vosperi and $B$. near pinnata) are from turbid waters, while a fourth, B. multidigitata may be. In fact many of Western Australia's endemic Branchinella inhabit moderately to highly turbid waters, other examples being $B$. complexidigitata, B. kadjikadji, $B$. halsei, $B$. mcraeae and $B$. denticulata Linder, 1941. Though it is tempting to relate their complex frontal appendages to the opaque environment in which they live, any relationship is not as simple as this. For instance some species with complex frontal appendages (e.g. B. arborea and B. campbelli) live in clear waters (Timms and Sanders, 2002). However clear evidence for the influence of living in highly turbid water is the reduction in eye size in $B$. pinderi.

All three widespread species studied here have some slightly different morphological features in the Western Australian populations compared with those in eastern Australia. Populations of $B$. compacta are slightly different morphologically between southwest Western Australia, western Victoria and southeastern New South Wales. Most amazing is the presence of a rudimentary frontal appendage in the New South Wales populations in a species diagnosed as not having a frontal appendage (Linder, 1941; Geddes, 1981). This strongly suggests that in those species of Branchinella without a frontal appendage ( $B$. buchanensis, $B$. compacta, $B$. hattahensis, B. nana, B. nichollsi, B. occidentalis, $B$. papillata, B. simplex and $B$. vosperi) the lack is secondary.

Differences across vast distributions are minor in $B$. compacta, a little more extensive in $B$. wellardi and almost great enough in $B$. pinnata to wonder about its specific status. Except for $B$. affinis, which initially was thought different enough to be given a variety name of wonganensis (Linder, 1941) the other species shared with eastern Australia show even fewer differences in the west. A similar situation applies to many other widespread crustaceans of Australian inland waters (e.g. Haloniscus searlei Williams, 1983). The enigma then is why there are so many endemic species of Branchinella (and Parartemia) in Western Australia, almost all of which have narrow distributions? The explanation probably lies in speciation being promoted by stability and great age of the landscape, adaptation to refuges in times of climatic stress and genetic isolation from eastern Australia (Pinder et al., 2004). Obviously despite these forces, some species have managed to maintain genetic interchange between west and east and maintain their integrity

\section{ACKNOWLEDGEMENTS}

I wish to thank Roger Hearn, Jane McRae and Adrian Pinder from the Western Australian Department of Environment and Conservation for collecting specimens and providing data, Melissa Titelius of the Western Australian Museum for facilitation of my studies there, to Stuart Halse for laboratory space at DEC's Woodvale Research Laboratories, and to D. Christopher Rogers for his helpful comments on the manuscript.

\section{REFERENCES}

Belk, D. (1998). Hotspots of inland crustacean biodiversity. Species 30: 50 .

CSIRO (2005). http://www.dar.csiro.au/impacts/ future.htm

Dakin, W.J. (1914). Fauna of Western Australia. II. The Phyllopoda of Western Australia. Proceedings of the Zoological Society of London 1914: 293-305.

Geddes, M.C. (1981). Revision of Australian species of Branchinella (Crustacea: Anostraca). Australian Journal of Marine and Freshwater Research 32: 253 295.

Hebert, P.D.N, and Wilson, C.C. (2000). Diversity of the genus Daphniopsis in the saline waters of Australia. Canadian Journal of Zoology 78: 794-808.

Henry, M. (1924). A monograph of the freshwater Entomostraca of New South Wales Part IV. Phyllopoda. Proceedings of the Linnean Society of New South Wales 1924: 120-137

Linder, F. (1941). Contributions to the morphology and taxonomy of the Branchiopoda Anostraca. Zoologiska Bidrag fran Uppsala 20: 101-330.

Milner, D.F. (1929). A description of two new species of Anostracan Phyllopoda from Western Australia. Journal of the Roval Society of Western Australia 15: $25-35$.

Pinder, A.M., Halse, S.A., Shiel R.J., Cale D.C. and McRae, J.M. (2002). Halophile aquatic invertebrates in the wheatbelt region of south-western Australia. Verhandlungen Internationale Vereinigung Limnologie 28: 1687-1694.

Pinder, A.M., Halse, S.A., McRae, J.M. and Shiel. R.J (2004). Aquatic invertebrate assemblages of wetlands and rivers in the wheatbelt region of Western Australia. Records of the Western Australian Museum Supplement 67:7-37.

Richters, F. (1876). Branchipus australiensis n. sp. Joumal des Museum Godeffroy 12: 43-44

Rogers, D.C. (2002). The amplexial morphology of selected Anostraca. Hydrobiologia 486: 1-18.

Rogers, D. C. (2006). A genus level revision of the Thamnocephalidae (Crustacea: Branchiopoda: Anostraca). Zootaxa 1260: 1-25

Sayce, O.A. (1903). The Phyllopoda of Australia, including descriptions of some new genera and species. Proceedings of the Royal Society of Victoria 15: $224-261$

Schwartz, K.Y. (1917). Results of Dr. F Mjöberg's Swedish scientific expedition to Australia 1910-1913. XV. 
Descriptions of two Australian phyllopods. Kungliga Svenska Vetenskaps-akademiens Handlingar 52(15): 7-8.

Timms, B.V. (2002). The fairy shrimp genus Branchinella Sayce (Crustacea: Anostraca: Thamnocephalidae) in Western Australia, including a description of four new species. Hydrobiologia 486: 71-89.

Timms, B.V. and Sanders, P.R. (2002). Biogeography and ecology of Anostraca (Crustacea) in middle Paroocatchment of the Australian arid-zone. Hydrobiologia 486: 225-238.

Timms, B.V. (2004). An Identification Guide to the Fairy Shrimps (Crustacea: Anostraca) of Australia. CRCFC Identification and Ecology Guide No. 47, Thurgoona, NSW 76 pp.

Timms, B.V. (2005). Two new species of Branchinella (Anostraca: Thamnocephalidae) and a reappraisal of the Branchinella nichollsi group. Memoirs of the Queensland Museum 50: 441-452.

Timms, B.V. (2007) The large branchiopods of gnammas (rock holes) in Australia. Journal of the Royal Society of Western Australia 89: 163-173.
Timms, B.V. and Geddes, M.C. (2003). The fairy shrimp genus Branchinella Sayce 1903 (Crustacea: Anostraca: Thamnocephalidae) in South Australia and the Northern Territory, including descriptions of three new species. Transactions of the Royal Society of South Australia 127: 53-68.

Timms, B.V., Datson, B. and Coleman, M. (2007). The wetlands of the Lake Carey catchment, Northeast Goldfields of Western Australia, with special reference to large branchiopods. Journal of the Royal Society of Western Australia 89: 175-183.

Williams, W.D. (1983). On the ecology of Haloniscus searlei (Isopoda, Oniscoidea), an inhabitant of Australian salt lakes. Hydrobiologia 105: 137-142.

Wolf, E. (1911). Phyllopoda. In Michaelsen, W. and Hartmeyer, R. (eds) Die Fauna Südwest-Australiens. Ergebnisse der Hamburger südwest-australischen Forschungsreise 1905, vol. 3: 253-276. G. Fischer: Jena.

Manuscript accepted 5 October 2007. 